\title{
The Gap between the Financial Mathematics Expressed in Textbooks and that Practiced in Banks
}

\author{
Maria Rachel Pinheiro Pessoa Pinto de Queiroz \\ Jonei Cerqueira Barbosa \\ Richard Noss \\ Celia Hoyles
}

\begin{abstract}
In this study, we aim to characterize the gap between the Financial Mathematics as expressed in textbooks and what is practiced in banking institutions. Three textbooks selected from public universities in the Brazilian state of Bahia were analyzed, and bank employees working in two banks in a city of the same state were observed. We noted different routines expected of participants in these two contexts, different problems faced and wide variation in the use of technology. Bank employees cope with client requests by interacting with bank systems in routines that include data selection to input into systems and the solution approach are organized around outputs as critical steps. However, this type of participation is also related to concerns about executing procedures with the security and agility required by the context's social practice. By contrast, Financial Mathematics reified in textbooks indicates pseudo-realistic exercises involving routines that include selecting models and calculation procedures as critical steps with only marginal use of technology, such as calculators.
\end{abstract}

Keywords: Financial Mathematics. Textbooks. Workplace. Gap.

\section{A Lacuna entre a Matemática Financeira Expressa em Livros Didáticos e a Praticada em Bancos}

\begin{abstract}
RESUMO
Neste estudo, nosso objetivo é caracterizar a lacuna entre a Matemática Financeira expressa em livros didáticos e aquela que é praticada em instituições bancárias. Analisamos três livros didáticos utilizados em universidades brasileiras situadas no estado da Bahia e observamos o trabalho de bancários numa cidade do mesmo estado. Evidenciamos diferentes rotinas envolvidas nesses dois contextos, diferentes tipos de problemas a serem solucionados e uma vasta variação no uso da tecnologia. As etapas críticas nas rotinas dos bancários são as formas de lidar com as solicitações dos clientes, interagindo com o sistema bancário em rotinas que incluem seleção de dados de entrada no sistema e solução dos problemas a partir de suas saídas. Contudo, essas formas de participação estão relacionadas com princípios relacionados a essa prática social que envolvem a execução desses procedimentos de forma segura e ágil. Diferentemente, a Matemática Financeira
\end{abstract}

Maria Rachel Pinheiro Pessoa Pinto de Queiroz é professora na Universidade do Estado da Bahia.

Jonei Cerqueira Barbosa é professor na Universidade Federal da Bahia.

Richard Noss é professor na University College London.

Celia Hoyles é professor na University College London.

Recebido para publicação em 31 jan. 2018. Aceito, após revisão, em 03 abr. 2018.

Acta Scientiae

Canoas

v. 20

n.2

p.96-116

mar./abr. 2018 
reificada em livros didáticos indica rotinas envolvendo a solução de exercícios pseudorrealísticos, tendo, como etapas críticas, a seleção de modelos e procedimentos de cálculo, com uso marginal de tecnologias, a exemplo de calculadoras.

Palavras-chave: Matemática Financeira. Livros Didáticos. Ambiente de Trabalho. Lacuna.

\section{INTRODUCTION}

In this study, the aim was to characterize the gap between the Financial Mathematics as expressed in textbooks and Financial Mathematics in the workplace. Particularly we look at the banking workplace. We do not necessarily imply that any gap is a problem, as the gap among different practices refers to their own nature: we will discuss this below. However, the main point underlining the present research is the way practitioners as textbooks authors or teachers deal with it is problematic and so it requires analysis.

Financial Mathematics is understood as the study, calculation or procedures arising from the 'time value of money'. This idea is that the value of money can be expressed as a function of time (Drake \& Fabozzi, 2009). Some examples of what we include under the heading of 'financial mathematics' are interest, discounts comparisons among different types of investment, annuities, amortization of loans and mortgages.

We acknowledge that practices comprise the historical and social contexts in which they are developed. Practitioners interact in shared activities, and learning is a process occurring from participation, an inseparable aspect of social practice (Lave \& Wenger, 1991). Reciprocally, in such interactions, practitioners modify these contexts. Moreover, it is important to recognize the diverse types of Financial Mathematics practices, for example, those practiced in colleges, banks, and securities companies. Considering these distinctions, in this study, we will refer to different mathematics practice as, for example, educational mathematics practice (the school, colleges or universities practices), professional mathematics practice (practiced by mathematicians), workplace mathematics practice (practiced by workers).

According to Hoyles et al. (2010, p.7), in technology-rich environments such as banks, there is specific knowledge related to how employees must address information systems, something they are only likely to learn when they become embedded in this workplace.

Referring to textbooks, they are recognizably part of teaching and learning processes in educational contexts because they are artifacts used by teachers to prepare their classes and by students as a learning support (Li, Zhang \& Ma, 2009; Rezat, 2006). As result, textbooks and actual practice mutually shape each other: textbooks can point to what students do in classrooms and, conversely, they can be potential resources to stimulate transformations in educational environments.

Furthermore, any study of the gap between workplace and explicitly educational contexts would benefit from considering the ways in which mediating tools define how practitioners come to act. According to Wertsch (1991), the mediational means used 
in a social practice characterize such a practice in terms of how participants act with these resources. For example, given that the media available in educational contexts are different from those used in banks, this theoretical lens provides some explanation of the gap between them. However, an analysis of the bankers-with-technology-in-practice can contribute to examining this unity to understand how it works and compare it to the type of mediated actions that textbooks seem to afford with the mediational means available in educational contexts.

\section{EDUCATIONAL AND WORKPLACE FINANCIAL MATHEMATICS: A DISCUSSION OF THE KNOWLEDGE GAP}

The discussion about educational and workplace Financial Mathematics generally comprises the presentation of studies focusing on the differences between educational and workplace-situated practices (Hoyles et al., 2010; Murphy, 2008; Noss \& Hoyles, 1996; Wedege, 2010; Williams and Wake, 2007). We understand the concept of practice (Wenger, 1998) as doings structured by historical and social context, in a way that it gives meaning to what practitioners do. Practice involves representations (like language, tools, documents, images, symbols, procedures, etc.) and practitioners' actions related to the social configurations they are embedded in, including their conventions, relations, rules, roles, purposes, etc.

The gap between academic mathematics and workplace mathematics has been welldocumented largely by Williams and Wake (2007), who have argued that the academic genre of mathematics values elegance, simplicity, and certain conventions and is in strict alignment with professional mathematics. Furthermore, they suggest that the academic curriculum should be designed to include other genres of mathematics practice rather than only the professional mathematics genre, for example, mathematics in the workplace with its ubiquitous use of technological tools. They argue for crossing the boundary of college and workplace systems, with potential consequences for both.

We understand boundary crossing as interactions between two or more social groups interconnected in an enterprise and organized around boundary objects and brokering (Wenger, 1998). According to Wenger (1998), boundary objects are forms of reifications like artefacts, terms, documents and concepts around which interconnections are organized, brokering the connections provided by people from one practice to another. Brokers are multi-membership people capable of making new connections across practices. For example, in Williams and Wake's (2007) study, spreadsheets were boundary objects while students, professor-researchers and some workers were brokers. That is, those individuals, when working together around the object were able to make connections between what they learned in college and what they were negotiating at the workplace.

In contrast to the studies above, Hodkinson (2005) argues that there are no differences specifically between learning in academic or workplace contexts. Rather these 
differences are due to any type of different context, for example, between two academic contexts or two workplace contexts. Therefore, according to him, if we are to understand the relationships between any of two different contexts, we need to look as the specific forms in which those relations take place, in particular circumstances. Billett (2011) provides an example. He showed that hairdressing apprentices in two different salons had to engage in different contexts because there were distinct rules for the division of labor, distinct hairdressing goals and distinct practices. Similarly to Hodkinson (2005), he concludes that there is a need for acknowledging and understanding localized requirements with expertise related to situational requirements.

Hodkinson (2005) argues that despite the dominant view that workplace and college learning are essentially different, the related argument that college-based learning is often irrelevant for workers is too simplistic. He goes on to provide examples of professionals who need high levels of theoretical knowledge, such as Medical Theory for doctors and Applied Sciences for engineers. However, according to Hodkinson, the latter is best learned in college.

Billett (2011) also argues for the importance of educational institutions in what he calls a learning curriculum. Drawing on a case study of his own personal curriculum, he constructed the idea of a learning curriculum as a collection of histories of learning in practice settings. As a result, he indicated that his engagement in both educational and workplace settings comprised his personal curriculum.

In our approach we assume that when someone moves from one context to another (at the same or even at a different time), his or her knowing is transformed by different interactions among people and practices in such contexts. Hoyles, Noss and Pozzi (2001) conducted a study about the knowledge of drug concentrations in nurses' practice and found that nurses' knowledge was intimately related to context rules and artifacts. They describe nurses' learning about drug concentrations in training courses in which the formal nursing rule ${ }^{1}$ was taught. Nurses repeated that rule in their wards, but not only the rule was negotiated by those nurses when addressing drug concentrations. The authors found that the calculations made by the nurses were 'structured by the packaging of the drugs, the social routines of administering the drugs, and the clinical effects of the drugs' (Hoyles, Noss \& Pozzi, p.23). This finding depicts a strategy highly dependent upon the context; in spite of being present in the ward, the nursing rule learned in advance (in training courses) was transformed through use.

We highlighted the term negotiated in order to clearly explain that it was not the word originally used by such authors. We used this word in this study relating it to Wenger's (1998) concept of negotiation, namely, a result of continuous interactions based on social relations, not about the scope of an agreement. Wenger (1998) uses the phrase negotiation of meanings to address the dynamic processes that entails both interpretation and action through which meanings are the product of their negotiation. Although it is not defined ${ }^{1}$ The nursing rule was described by these researchers as $\frac{\text { whatyouwant }}{\text { whatyou'vegot }} x t \frac{\text { whatyouwant }}{\text { whatyou'vegot }} x$ theamountitcomes $\in$ and
was described by Pozzi et al., as being like a "mantra". 
in the studies we referred to above, we can conclude that meanings are intersubjective understandings regarding objects through continued interactions that are socially and historically constituted through negotiation and re-negotiation in the contexts from where they emerge. This justifies why we often prefer to use the word knowing (instead of knowledge) when addressing the process by which people come to know, negotiating shared meanings in their practice.

As part of educational practices, Financial Mathematics textbooks encapsulate collective knowledge in this area. They are artifacts around which people can connect the local experience of the classroom to the global view of many different practices involving, for example, mathematics for finance coming from scientific, workplace practices. Therefore, they can be used to afford an alignment between educational and professional practices by changing the experience of students mastering their curricula into a more fluid path between college and work.

\section{THE ROLE OF TECHNOLOGY IN THESE ENVIRONMENTS}

We shall discuss here how the different artifacts and roles of technology shape the gap between educational and workplace mathematics. We start with Zevenbergen (2011), who approaches this issue by showing a change in retail-industry work requirements. She focuses on how young workers (born after 1980) participate in this field by adopting new ways of working, often different from those of past generations. According to her, arithmetic tasks are now often performed by technology, and there are other requirements in this field of work, such as the use of estimation, problem solving, the use of technological tools to support their work, and social forms of participation such as assisting a client and working with peers.

Hoyles et al. (2010) also noted this change and the new demands made at work and coined the term Techno-mathematical Literacies $(\mathrm{TmL})$ to address the role of information technology (IT). They explain this type of literacy as one that involves a language that is not mathematical, but techno-mathematical, where the mathematics is expressed through technological artefacts' (p.14, emphasis added by the authors). By this notion, they acknowledge the use of mathematics as a language that increasingly pervades the workplace through IT-based systems, an idea shared by both Williams and Wake (2007) and Zevenbergen (2011).

In educational settings, there are some studies that show how mediational tools shape students' knowing. For example, Rivera and Becker (2004) report the mediating roles that handheld graphing calculators (in this case, the TI-89) play in students' mathematical understanding about polynomial inequalities. According to them (Rivera \& Becker, p.87), 'both the TI-89 and other learners mediated in ways that made it difficult to analyze the influence of one apart from the other, which is but an effect of instrumented activity'. In these studies, technology is viewed in socio-cultural contexts; in other words, technology is a human outcome and, at the same time, structures humans' knowing. By means of 
continuous interactions, humans use and improve such meditational tools, affecting and being affected by them.

Though there are similarities between workplace and educational contexts in terms of the impact of mediational tools, the role of technology in educational contexts is qualitatively different from that in workplaces. In workplaces, technology pervades the work culture and structures how people act in these practices. Workers must address inputs and outputs of systems (Hoyles et al., 2010) to perform a task; and understanding the embedded mathematics is not a simple process (Noss \& Hoyles, 1996; Williams \& Wake, 2007). By contrast, the use of technology in educational institutions aims at different goals, in this case, related to the teaching and learning practice (Rivera \& Becker, 2004). In this case, understanding the embedded mathematics is the goal.

The question we address is what are the differences between the Financial Mathematics negotiated by bankers and the Financial Mathematics knowledge expressed in textbooks? To answer that question, we followed the work of employees from two banks in Brazil and analyzed three textbooks referenced in public universities of the Brazilian State of Bahia.

\section{CONTEXT AND METHODOLOGICAL PROCEDURES}

Our major interest is to understand the meanings negotiated in the different contexts described above in order to characterize any gaps between them. We therefore followed qualitative approach (Denzin \& Lincoln, 2005). In the bank context, we sought to understand the practice of Financial Mathematics by analyzing bankers, what they do and the related negotiation of meanings conditioned by technology. In the textbook context, we investigated how Financial Mathematics knowledge is expressed and organized.

The textbooks were selected on the basis of the descriptions of the Financial Mathematics subject in business courses, and professors' answers about the textbooks used to prepare their classes and/or suggested to their students in public universities in the state of Bahia, Brazil. We collected descriptions from four different universities and answers from professors at three of these universities by e-mail. The selected textbooks were those present in at least two of these descriptions and two of the professors' answers: Matemática Financeira by Washington Franco Mathias and José Maria Gomes (2011), Matemática Financeira by Carlos Patrício Samanez (2010) and Matemática Financeira by José Dutra Vieira Sobrinho (2013).

We analyzed these textbooks by following the procedures suggested by Charmaz (2005), i.e., by creating codes and categories for data in these textbooks. We coded these data through each line and each page, observing their form and content in some chapters. Priority was given to internal aspects (Oliveira, 2010) of these textbooks, trying to understand reified meanings in the books that can give clues about what possibly happens in the classroom. As noted by Oliveira (2010), studies that aim the classroom have a more pragmatic function, thus, we chose to analyze only the internal aspects because we understand that they are sufficient to meet our goal. 
Concerning the content of the books, we analyzed concepts, procedures, demonstrations, and the books' relationship to Financial Mathematics' everyday practices and language. We also analyzed the solved and proposed exercise types, their solutions, interpretations, alternative solutions and answers, including calculation details and possible uses of calculators. In relation to form, we observed the books' chapter structures, language, visual representations such as graphics and diagrams, appendices and their uses.

In the bank context, we conducted observations (Angrosino, 2005) as a data collection procedure because doing so enabled us to be in direct contact with such a practice. The observation was performed by the first author of this study in two banks in a middle-sized city in the State of Bahia. We selected two of the major banks from that city. In each of these banks, observations were undertaken each lasting three (3) days for approximately six (6) hours each day, ranging from December 2010 to January 2011, thirty-six (36) hours in total. The data collected were described in a field notebook.

Managers were concerned about banking secrecy, but the researcher explained that, according to the study goals, she would not be taking notes of clients' private information and would place her annotations at the managers' disposal thereafter. We assured them we would preserve bank, employee and client anonymity. Because bank employees are the subjects of this research, although data are presented, we use pseudonyms to maintain the promised anonymity.

Thanks to banking secrecy, it was not possible to use audio or video recordings to register the collected data. It was only possible to register the data in a field notebook, which enabled selecting information pertinent to the research, thus avoiding the exposure of data involving clients' private information.

It was possible to observe bankers when they were assisting their clients and during the internal work, when they were not in such a hurry. In both banks, we observed bankers in practice in several sectors, such as the personal banking service, business-banking service, credit room, housing sector and tellers' group. For example, the first author seated beside bankers of these sectors when they were attending to their clients taking notes in the field notebook. When an action was not clear, questions were made to the bankers soon after the client left. Only tellers were observed from the outside because their workplace is for staff only.

The researcher also undertook non-structured interviews (Fontana \& Frey, 2005) with some of the employees concerning their practices in the context of observation as a means to better understand them and thus enable them to approach freely the topic under study. For example, during internal work, a manager of the business bank sector explained about factoring operations and freely talked about the bank's system and about employees learning. This happened before the interview moment when he was answering to questions made by the researcher. The interviews were conducted by the researcher to unpack issues about the employees' relation with the Financial Mathematics practices in the bank alongside their use of the banks' systems. But, sometimes, these types of information were freely given by the bankers, during the observation, in moments not 
expected by the researcher to be an interview moment as in the example described before. Bankers chosen for the interview were selected according to the following criteria: (1) bankers who were managers (of Personal Banking, Business Banking and Tellers' Group) and, therefore, for that reason, had more information about the banks' routines and (2) bankers who had greater availability of time and who had been shown to be more solicitous during the data collection (as was true of a banker trainee).

The field notebook (of the banks') analysis began by examining and coding the data line by line. These excerpts were selected through incidents observed in the bankers' actions that would be useful to achieve our goals. According to Charmaz (2005), such codes show how we select, separate and organize the data to start the analysis. Then, we categorized these data segments according to the participants' actions. In each category, we labeled the bankers' actions with their associated properties.

The data collected from the textbook and from the bankers' practice were organized into tables following those categories formed to obtain cases in which the data were transversal to both. We associated these transversal findings to new categories presented in the following section.

\section{DATA ANALYSIS}

The data collected in the banks showed us that the Financial Mathematics banking practice is organized according to system information, which plays a central role in how bankers act. Conversely, the textbook analysis showed that procedures about solving pseudo-realistic exercises are central to how Financial Mathematics knowledge is organized for educational purposes. These exercises are called pseudo-realistic because they express situations that intend to be a typical Financial Mathematics situation in the workplace or everyday practice. We organized the next subsections according to these contexts, showing the different routines that characterize each of them, what problem is to be solved, the different approaches to problem solving and the different roles of technology in these environments.

\section{CHARACTERISTICS OF ROUTINES IN BANKERS' PRACTICE AND IN FINANCIAL MATHEMATICS TEXTBOOKS}

Bankers' practice is organized with information systems playing a central and pervasive role. The data collected about Financial Mathematics bankers' practice are related to what they do when working with the system. We will present each finding by naming the critical steps, indicating those that require more effort from bankers, in term of time, actions and negotiation of meanings. 
First, bankers must select the data available according to clients' requests to feed the system ${ }^{2}$. Clients' discourse contains not only information and requests but also, for example, wishes, complaints, and life histories. For example, a client seeking funds to buy a car mentioned the car's price but Gustavo (a banker working in the credit sector) told him that it was higher than the value offered by the system for a car with the same characteristics (Field Notebook, p.4, lines 5-8; 17-21). In other words, the information that bankers really need to feed into the system (for example, the list price of a car, the present value for a loan, etc.) is mixed with all types of personal information provided by clients. The bankers must coordinate, based on the information available, what actually matters to feed the system. That is why we can label this step as critical.

After bankers input the selected data, the bankers follow the calculation procedure step in which everything is performed by the system. This step is therefore not critical in terms of bankers' actions, they have no control over its outcomes. Then, the system makes available some outputs that are used by bankers to accomplish the task.

This final step, which involves the bankers' use of the system outputs, is considered critical: the bankers must interpret the system outputs and, in some cases, coordinate these outputs with customers' contexts and profiles to accomplish the task, as we will see in the following examples.

Occasionally, bankers advise their clients of the best alternative, for example, loans or investments. This guidance requires coordinating work with the system. The system shows possibilities for one of these operations, but it is the banker's task to advise the client in his decision, financially speaking, considering the client's specificities. For example,

[Marcos says that] it is very important [to have a notion of what is being performed by the system] for the analysis to advise the client. For example, the bank offers two (2) modalities of amortization systems: SAC [abbreviation in Portuguese that refers to a constant amortization system] and PRICE. He must know how they work to know what is better for the client. He [Marcos] gave an example: a client can ask for a loan but states that he wants to settle it within 3 months. In this case, because of the evolution of the debt balance, the type of spreadsheet and the rate charged, he can advise the client on what alternative is the best for him or her under those circumstances. (Field Notebook, p.27-28, lines 22-26, 1-9)

In this case, Marcos (the Business Banking manager) needed to know the principles ruling each amortization spreadsheet to advise the client in that specific loan situation. On the one hand, in the 'Constant Amortizations System' (in Brazil named 'Sistema de Amortizações Constantes' - SAC), amortizations (restitution of the main capital lent) are constant, and installments decrease. On the other hand, using the 'French System' (in Brazil named 'Sistema Francês', on which the 'Price' table is based), amortizations

${ }^{2}$ We use this metaphor to address the kind of data that the bankers have to input to fulfill the information that the system requires to work. 
increase, and installments are constant. Therefore, in the second case, during the first installments, the client will have amortized a lower part of his debt, which is not interesting for those immediately wishing to settle the loan. Then, knowing these principles, Marcos can better advise his clients, something the system cannot do.

We found another case such as this one, in which Laura (the Personal Banking manager) advised her clients about the best investment by considering their profile. In both cases, we can state that even with bankers who needed the system to accomplish the operations and not having a need for making calculations, their advice concerning the alternatives of loans, financing or investments were decisive in assisting the client's decisions because this advice referred to better conditions for clients in particular situations. These evaluations cannot be conducted by the system.

These bankers (in these cases, the managers) used their previous knowledge of Financial Mathematics principles and procedures to better advise their clients. Thus, we consider that bankers' actions in these cases involve financial analyses that extrapolate from the systemrestricted use. In summary, we claim that bankers' routines involve ways of working with the bank systems, and their actions were imperative in selecting data to input into the system and in providing solutions addressing their clients' requests, using financial analysis.

In contrast to the bank context, analysis showed that what is central in the Financial Mathematics reified in textbooks is solving exercises. Therefore, identifying ways of solving exercises is routine in this context. The exercise-solving routine proposed by the textbooks analyzed involves basic steps that exist in all exercises presented in this study and some other steps that occur only in some situations, which we called variations.

The exercise-solving routine follows some standards, providing pathways to be accomplished by the solver to make the process easier. The first step is usually presenting a list of values of known variables as data provided by the exercise description, followed by the unknown variable presented with a question mark and the formula to be used. This step represents a transition from the current language to the mathematical one, as shown in the translation of the exercise (Vieira Sobrinho, 2013, p.26) in Figure 1.

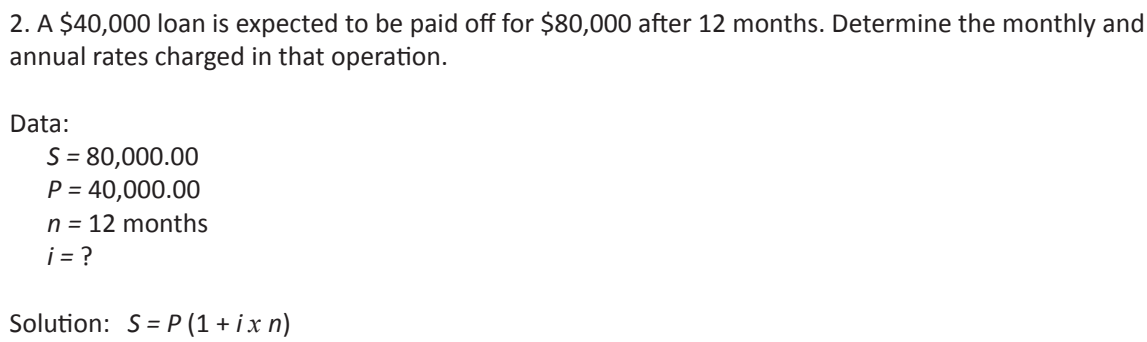

Figure 1. Presentation of data in an exercise (Vieira Sobrinho, 2013, our translation)

This step, in a sense, is close to the one that bankers must follow to feed the system. The main difference is that the situation to be interpreted by bankers can involve many 
variables, some relevant and some not, which they must sort out, whereas in the exercises, the data provided are usually exactly those needed to solve the exercises. That is, exercises are simplified situations in the sense that all the required data, but no extraneous data, are presented in the exercise description.

The following step is the calculation procedure. Known variables in the formula are replaced with their values, and the algebraic transformations required to achieve the unknown variable value are applied. Occasionally, there is more than one pathway, and alternative ways are usually presented in the solved exercises.

An example is an exercise (Mathias \& Gomes, p.104-105) involving calculating the rate for a compound capitalization in which the procedure is explicitly performed following the formula in this model, as shown in the translation of the exercise on Figure 2.

$$
\begin{aligned}
& \text { b) } C_{\Omega}=1,125.51 \\
& \mathrm{C}_{0}=1,000.00 \\
& n=4 \text { months } \\
& 1,125.51=1,000.00(1+i)^{4} \\
& \frac{1.125,51}{1.000}=(1+i)^{4} \\
& 1,125.51=(1+i)^{4}(\text { seetableappendix }) \\
& \text { For } i=3 \% \text { and } n=4 \text { (months), }(1+i)^{n} \cong 1.12551 \text {. } \\
& \text { Therefore, the rate is } 3 \% \text { per month } \\
& \text { Using Nth rooting: } \\
& (1.12551)^{1 / 4}=(1+i) \\
& \text { In logarithms: } \\
& \begin{array}{l}
\frac{1}{4} \log 1,12551=\log (1+i) \\
\frac{1}{4}(0,051349)=\log (1+i)
\end{array} \\
& 0.012837=\log (1+i) \\
& \text { Extracting the antilogarithm: } \\
& (1+i)=1.03 \\
& \therefore i=0.03 \text { or } 3 \% \text { per month } \\
& \text { Root calculation by iterations: } \\
& i_{k}^{\prime}=\frac{0,12551}{4}=0.031378 \\
& 1+i_{k}^{\prime}=1.031378 \\
& \left(1+i_{k+1}^{\prime}\right)=\frac{3}{4}\left[1,031378+\frac{1,122551}{(1031378)^{3}}\right] \\
& \left(1+i_{k+1}^{\prime}\right)=1.03000
\end{aligned}
$$

Figure 2. An exercise showing calculation alternatives (Mathias \& Gomes, 2011, our translation) 
After replacing the data in this formula, the gain factor is obtained, to which there are four calculation alternatives, i.e., looking up the value in the Appendix tables at the end of the book; by root extraction; using logarithms; or by iteration, using Newton's recursion formula. Note that in this case, four calculation alternatives were explained, but the alternative use of the calculating machine was omitted. We did not observe situations similar to these routine procedures to solve exercises in the bank practice because all types of calculations are performed by the system.

In the textbooks' exercises, solutions result from the calculations performed, by means of algebraic transformations or with the help of a calculator. In many of these exercises, the final value of the unknown variable appearing at the end of the calculations is accepted as the solution to the exercise. Displaying the value of the unknown variable seems to be sufficient. In other exercises, there are verbal conclusions to the solution or interpretations to achieve the solution, but the solutions are always unique. The goal of solving the exercises is reaching this unique solution.

In summary, routines in banks largely involve selecting data to feed the system, interpreting the systems' outputs, and using the systems' outputs to solve clients' requests, along with the interpretation of the context and clients' profiles. Differently, textbook routines largely involve using and interpreting the data available in the exercises, deciding which models fit the situations, selecting types of calculation procedures, and reaching 'the' solution using algebra.

Although critical steps performed by bankers are data selection and occasionally the solution approach using system outputs, in the textbook exercises, the critical steps are calculation procedures. On the one hand, in banks, there are no tasks similar to textbook calculation procedures because everything related to this type of step is performed by the system. On the other hand, in the textbooks there are no similar pathways such as data selection or the decision-making process experienced by bankers because exercises are simplifications of the situations they intend to simulate, and the solutions are always unique and are not context dependent.

\section{Tasks identified in bankers' practice and in Financial Mathematics textbooks}

Here tasks refer to what someone is required to do. The bankers faced many distinct types of tasks when assisting their clients. Examples include instructions provided to clients and fulfilling a loan operation (Field Notebook, p.58, lines 13-16), simulating proposals for housing loans (Field Notebook, p.69, lines 13-25), advising clients on choosing the best option for funding (Field Notebook, p.27-28, lines 22-26, 1-9) and investments (Field Notebook, p.87-88, lines 23-26, 1-9). 
The most complex tasks observed in managers' actions were addressing different possibilities for funding (system outputs) when advising clients according to their specific situation (Field Notebook, p.27-28, lines 22-26, 1-9) and helping them choose the best investment alternative according to their profile (Field Notebook, p.87-88, lines 23-26, 1-9). In such cases, even with bankers using the system to accomplish the operations and not having the need for making calculations, their advice concerning loan alternatives, financing or investments were decisive in serving the client.

In the case of the Financial Mathematics in textbooks, the apparent task is learning how to cope with different approaches and procedures to solve the exercises. Examples include understanding the descriptions of exercises and translating their data into mathematical language; learning to use the technology available to help with the calculations; and choosing the pathways, formulas and calculation procedures to achieve the solution.

The exercises are situations that reference workplace problems or everyday practices, occasionally closely but occasionally too detached from the actual situations. Some of these exercises have been most likely selected for didactic reasons, given their distance from the situations actually happening in workplace and everyday contexts. Despite the effort to illustrate situations in these contexts, particularly in Samanez's textbook, none of the bankers' main actions discussed above was represented in the exercises analyzed.

There are exercises in which the descriptions call for decision-making, but the solution proposed is too simplistic or even detached from actual possible solutions to the situations they intend to represent. An example is exercises requiring comparisons of alternative purchases or investments (Mathias \& Gomes, p.122, 144, 147, 151; Samanez p.103; 104); however, the solution is always a pure Financial Mathematics result evaluating different solution possibilities according to their context. That is, the exercises show offers related to different payment possibilities, usually comparing payments at a future date to payments in the present or two distinct series of payments, with a lower or higher number of installments with interest rates involved. Moreover, we observed few examples in the textbooks analyzed requiring any decision making.

The overarching difference between the tasks really experienced in the workplace and everyday practices and the exercises reified in the textbooks is that the latter are not workplace problems at all. The textbook problems are structured to be simple, in the sense that they must present only the data really needed to solve them, and the solution is always unique; therefore, it usually is very detached from actual tasks, such as those in which bankers had to analyze situations and clients' profiles to help them during the decision-making process. Therefore, we conclude that the actual task in the Financial Mathematics reified in textbooks is addressing the pseudo-realistic exercises (Skovsmose, 2000) that intend to simulate problems of professional and everyday environments but that usually are not very close to doing so. 


\section{The role of technology}

In banks, technology pervades all of the bankers' practice as displayed in the sections above. The bank information systems play a central role in this practice as stated by a banker:

The general manager in bank A, [...], immediately said that everything was performed in the system. (FIELD NOTEBOOK, p.101, lines 5-7)

As only to be expected, the observed bank operations were performed with the information system. Even when bankers used their previous knowledge of principles and procedures of Financial Mathematics to advise their clients better, as shown in the sections above, this guidance required a task coordinated with the system. Another approach to interacting with technology occurs when bankers must assist their clients in their companies (out of the bank). In this case, banker stated that they usually take their financial calculators to perform their work, but they must return to the bank to complete the operation within the system.

These information systems were introduced and improved in the banks for effectiveness and security, as seen in some bankers' discourses. For example, according to Evandro (a manager in one of the banks observed),

The system does everything to gain security and service agility, minimize the occurrence of error and maximize productivity (Field Notebook, p.47, lines 18-21)

Differently, textbooks shows that suggestions provided using calculators or electronic spreadsheets (media referenced in the textbooks analyzed) were not central to routines of the Financial Mathematics reified in these books.

For example, in the Samanez (2010) textbook, we found many suggestions for the use of calculators, including steps to calculate with the HP $12 \mathrm{C}^{3}$ and its linked procedure functions, as shown in the translation of the example (Samanez, 2010, p.39) in Figure 3.

\footnotetext{
${ }^{3}$ The HP 12C is a financial calculator; according to Caramori (2009), it is the most popular one in Brazil.
} 


\section{Example 3.3}

What is the surrender value for capital of $\$ 200$ applied at the following terms and rates?

a) 27 days at $9 \%$ per month, capitalized on a daily basis $(j=0.09$ per month, $k=30, m=27 / 30$ months)

$$
\begin{aligned}
& S=P\left(1+\frac{j}{k}\right)^{k x m}=\$ 200 x\left(1+\frac{0.09}{30}\right)^{30 x(27 / 30)}=\$ 216.85 \\
& \text { HP 12c Calculator: } \\
& \begin{array}{|l|l}
\hline \text { (f) (FIN) } & \text { erases the financial memory }
\end{array} \\
& 9 \text { [ENTER] } 30(\div) \text { (i) interest rate per capitalization period } \\
& 27(\mathrm{n}) \quad \text { number of days from the deadline } \\
& 200 \text { (CHS) (PV) capital with a minus sign } \\
& \text { (PV) } \rightarrow 216.85 \text { calculates the amount }
\end{aligned}
$$

The deadline was converted into the same unit of time as the nominal rate ( $m=27 / 30$ months).

Figure 3. Exercise including steps to calculate with the HP 12C (Samanez, 2010, our translation)

In many of these exercises, there are also algebraic alternatives to accomplish the solution. Additionally, references to spreadsheets were found in an appendix at the end of this textbook entitled 'Financial Mathematics with Excel' (our free translation). In this appendix, the author presented the software details, financial functions and applications. In any case, the use of technology was suggested to improve calculations by gaining agility.

In Vieira Sobrinho's (2013, p.40) textbook, there are suggestions of simple scientific calculators included in the book. Although he occasionally refers to financial calculators in the book, he only includes in the last chapter instructions on how to use them.

In Mathias and Gomes' (2011) textbook, the exercises solved are presented in detailed steps of calculation procedures, showing pathways to develop them (Notebook, p.9, lines 13-14). In the first chapters, there is no suggestion about the use of calculators or spreadsheets (Notebook, p.9, lines 10-17) and alternative means of solving exercises seem to be ways to handle calculations and avoid the use of calculators, such as in the example presented in the first subsection of this analysis (extracted from pages 104 and 105).

The calculation strategies presented throughout this textbook are linked with some principles provided in the authors' presentation, in which they state, 'the educational experiments with calculators and even with software spreadsheets have demonstrated that the process of analytical reasoning precedes the use of a calculation tool' (Mathias \& Gomes, 2011, presentation, our translation). We could reasonably conclude by the authors' discourse that what is valued, recognized and legitimated in this textbook is providing options to solve exercises without using technology. 
In general, the use of these technology suggestions is at the margin in the sense that they are presented (when they are) as alternatives to algebraic calculations to gain agility to solve exercises. We did not find, in any textbook, any use of technology to enable mathematical investigations for educational purposes.

Therefore, in textbooks and in banks, the role of technology clearly is to gain agility, but in a very different way; in the former, technology plays a marginal role, whereas in the latter, technology pervades all of the bankers' actions.

\section{DISCUSSION}

We can say that bankers' routines have critical steps in data selection and in the solution approach to problems presented by their clients. Bankers' actions are centrally shaped by the bank system according to the goals and principles of this practice, i.e., solving clients' requests with security and agility. Such behavior is possible due to the technology made available, in this context, by banks' information systems, which are mixed with humans' actions, producing an inseparable set referred to by Wertsch (1991) as individual(s)-acting-with-mediational-means. We prefer to term it individual(s)-actingwith-mediational-means-in-context to address how tasks, goals and principles of this practice govern the use of the available technology. We understand the word principles as historical and social pattern settled down on a practice, which is based on recognized rules in the social group involved.

This set is in tune with what is made available by the bank systems to improve bankers' work and the actions that systems cannot perform by themselves, as addressed in the sections above, but that can be provided by humans. In other words, the outcomes and solutions to tasks is possible not only because of what the system or humans can do BUT also because of what this set can do according to principles governing such practice.

In the case of Financial Mathematics expressed in the analyzed textbooks, we could infer that the task in this context is to solve exercises properly. Solutions are realized via the use of a multitude of algebraic procedures (pure mathematics resources) in the core of most exercises. The technology available is used at the margin because of the presence of other objects more valued in this practice, according to their principles, as algebraic procedures. Again, we ascribe the use of technology to the tasks, goals and principles reified in the textbooks. Perhaps it indicates that they potentially also govern the practice of teaching and learning Financial Mathematics.

The procedures expected to solve the exercises properly are the critical steps. Such steps are not seen in bankers' practice because they are performed by the system. Conversely, the data selection steps and approaches to solutions experienced by bankers were not seen in the textbooks because those exercises are simplifications of situations they intend to be, with a unique solution.

We have detailed what makes such Financial Mathematics practices so different. Henceforth, we will discuss why they are so different. For example, why is the technology 
available and used in banks so indispensable in this context, whereas the use of technology suggested in the textbooks is so dispensable and marginal?

On the one hand, as shown previously, the use of the bank systems provides agility and security to this practice, and these things are highly valued in this practice. On the other hand, the use of calculators and spreadsheets (the technology referred to in the textbooks) remains at the margin despite some studies (Bakker et al., 2006; Rivera \& Becker, 2004) showing the importance of technology to learning in education settings.

After organizing these ideas, we can say that each context has tasks and goals interrelated with the principles that govern the context. In turn, this triad (tasks, goals, and principles) is interrelated with the routines, their critical steps reported previously and the technology used.

We propose a means of analyzing the specific relationships between the Financial Mathematics practiced by bankers and the one reified in the textbooks. Our wish is understanding their specificities, what the differences between them are and why they are so different so we can derive insights about how to deal with it. The drawing on figure 4 can help us understand these instances and their relationships.

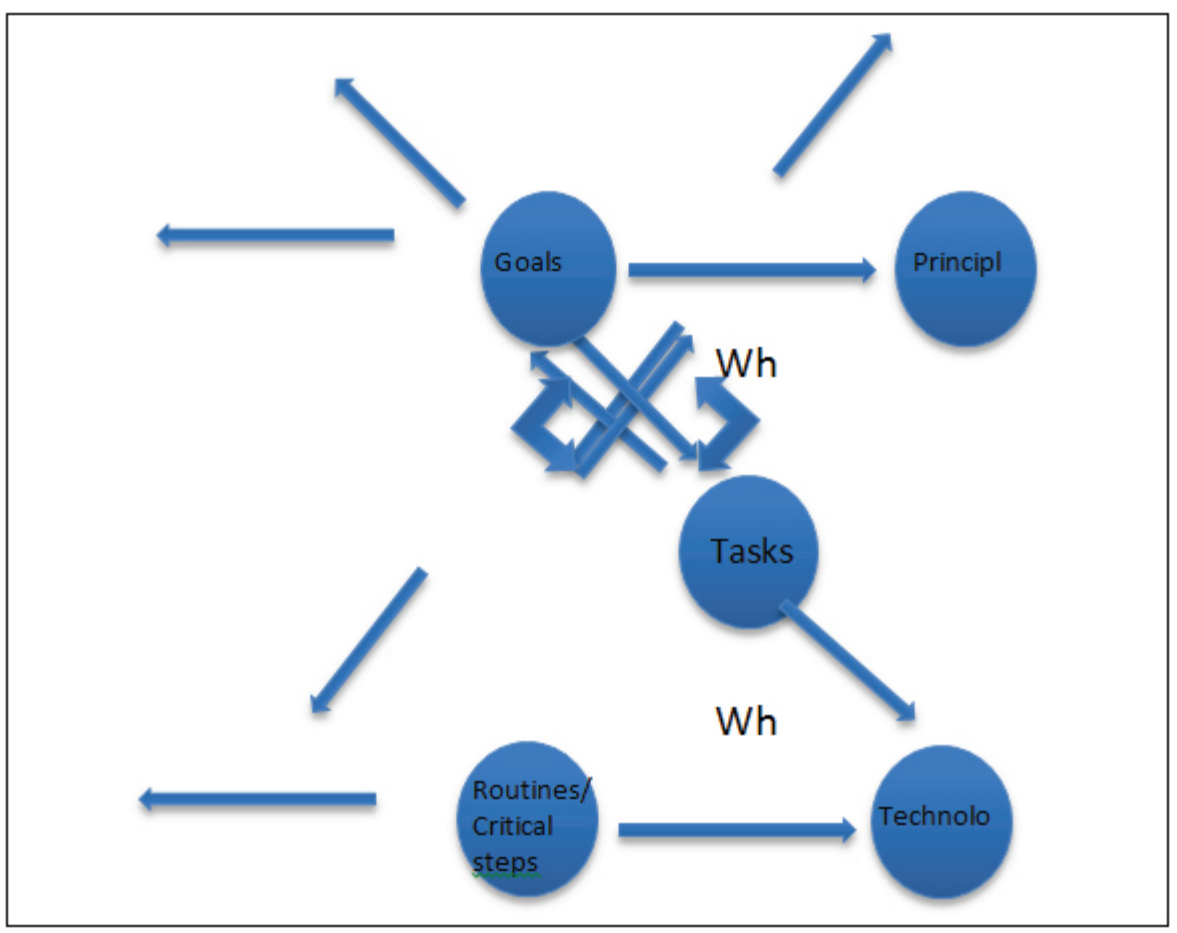

Figure 4. Relationships among problems, goals, principles, routines and technology in a context 
This drawing depicts two triangles representing a context. They are linked by a core node, which we call 'tasks' referring to what is required in a particular context. On the one hand, goals, principles and tasks in a context frame the first triangle represented by this triad. On the other hand, tasks in the node are linked to routines, their critical steps and the technology used in a context, framing the other triangle, which is, in its turn, linked to the first one by this very node. By relating this drawing to the analyzed contexts, we can recognize interrelated systems.

Tasks in the bank practice related to clients' requests are linked to goals and principles governing this practice, namely, solving their clients' requests with effectiveness and agility. This triad is linked to the other one represented by the tasks themselves, the routines required to solve such tasks (detailed in previous sections), with the data selection and the solution approach as critical steps, and the banks' systems. Each (imaginary) line of the triangles represents a dual relationship (arrows) between the vertices. As examples, in banks, goals and principles are interrelated just as, for example, tasks are related to technology, with tasks having a node that links the first triad to the last one.

In fact, bankers' routines and their critical steps, represented by data selection and the solution approach, are linked in a dual way to the technology used because they are linked to tasks presented in this context. By the node represented by tasks, we can also link, for example, the use of banks' systems to principles governing such a practice. That is, their use provides agility and effectiveness when solving clients' requests.

In the textbooks, the task of solving exercises is linked in a dual way to the educational principles reified in the textbooks. For example, the tasks offer a multitude of algebraic pathways to accomplish this task. As a result, the marginal use of technology is linked to these tasks and principles and to the critical steps identified in the exercisesolving routines.

From this analysis (and the figure we designed), we could address what are the specific differences between the bank context (and all the kinds of task that depend on financial decisions linked to bank operations) and educational contexts and why are them so different in order to rise insights for professional preparation in business courses. But more than that, we offer a way to analyse any two different contexts (even two educational contexts or two workplace contexts, technology-rich or not), a need for acknowledging and understanding localized requirements with expertise related to situational requirements as Hodkinson (2005) and Billett (2011) asserted. This way of analysis consider that the characteristics (what) of each practice are always linked to the goals and principles via the tasks imposed in each one. For example, let us consider the task of hairdressing in the case of two different salons addressed by Billett (2011). In the first one the task of hairdressing could be started by one hairdresser and finished by a most senior one, whereas in the other salon the same hairdresser undertakes the entire hairdressing task. In the first one, when a new hairdresser was in engaging in this practice, a path of activities, beginning from cleaning and tidying the salon till curling, coloring and cut women's hair had to be accomplished. In the second one, the newcomers were required to cut and color independently much earlier. These different requirement (associated to the goals and to 
what was valued in these contexts) show why the tasks held to be more difficult (problem) were linked to the routines of hairdressing (what) in each salon.

That is, the identified factors that constitute any particular context (educational, professional and so forth) can be compared to another one by this type of analysis offered (showing the characteristics of a gap) and these comparisons can potentiate studies related to professional preparation.

\section{CONCLUSION}

Our purpose was to build an understanding of the differences between the Financial Mathematics negotiated by bankers and the Financial Mathematics knowledge reified in textbooks. However, instead of only providing an answer about what are these differences, we also answered why they are different.

We observed these whys when analyzing the bankers' practice, particularly what was recognized as legitimate and valued in this context and comparing it to what was considered legitimate in the textbooks. Although the whys were not our initial pursuit, they were so linked to the data and to the theory adopted that we could not disconnect them from the what.

We are not saying that overcoming the differences between the Financial Mathematics reified in the textbooks and bankers' practice is possible or even desirable: they are different contexts, they have different purposes, etc. However, we are able to cross some boundaries laying out insights for educational contexts inspired in the requirements for workers that depend on financial decisions. For example, textbooks can afford decision making exercises that depends on contexts of potential clients or companies in specific situations requiring not always a unique solution approach (as seen in Marcos' advise to his client in the bank). Yet, evaluating different solution possibilities according to their context considering that the pure Financial Mathematics solution is occasionally detached from what would most likely happen in fact (for example, someone whose refrigerator is out of order who needs a new one, but does not have the money immediately at hand, will probably choose to buy it in installments, even if he or she will pay some interest; a company who needs to make an investment and would not like to spend its floating capital, sometimes chooses to ask for funding and will have to pay for that amenity). These types of negotiation of meanings that are more close to those practiced in everyday or workplace contexts can help students starting their professional lives moving from educational to workplace contexts in a more fluid pathway.

We observed this kind of choice in a textbook entitled Mathematics for Finance (Capinski \& Zastawniak, 2011), which presents case studies arising from workplace contexts to be analyzed by readers. Although it is impossible to expect the same kinds of problems and tasks between educational and workplace contexts, the use of such case studies, showing other ways of doing things, reinterpreted by students in new terms, can provide readers' engagement in problems similar to that ones experienced by workers. 
The examples considered before show that we can expect textbooks to be able to afford students educational experiences that can potentiate their future participation in their professional lives, constituting their learning curriculum (Billet, 2011). However, despite attempts to use repertoires and examples of operations that resemble those practiced in the financial market, we verified, in the textbooks analyzed, a reification of Financial Mathematics practices very different from workplace practices. This gap is visible in the tasks shown for each context, linked to the routines, their critical steps, and the technology as well as the tasks, goals and principles governing each one.

We acknowledge that the characteristics of this knowledge reified in the analyzed textbooks are not sufficient to understand educational practices, nor do the characteristics of the bankers' practice observed comprise the multitude of financial workplace practices. But we consider that the observation of some bankers' practice in a highly regulated institution (that hardly permit outsiders' observations) enabled us to report financial operations conducted on banks, findings not easily found in the literature review, that helped us to set an structure to the gap researched and maybe sow other ones. Further, this study might serve as a springboard for other studies showing that educational contexts should try to create situations that represent bridges to that ones experienced by workers to prepare students for their professional environment, supported by the role of professional education in business courses.

\section{REFERENCES}

Angrosino, M. (2005). "Recontextualizing observation: ethnography, pedagogy, and the prospects for a progressive political agenda". In The Sage Handbook of Qualitative Research, edited by N. K. Denzin and Y. S Lincoln, 729-745. Third Edition. London: Sage Publications.

Bakker, A., Hoyles, C., Kent, P., \& Noss, R. (2006). "Improving work processes by making the invisible visible". Journal of Education and Work. 19(4), 343-361.

Billet, S. (2011). "Workplace curriculum: practice and propositions". In Theories of Learning for the Workplace: building blocks for training and professional development programs, edited by F. Dochy et al, 17-36. Oxon: Routledge.

Capinski, M., \& Zastawniak, T. (2011). Mathematics for Finance: an introduction to financial engineering. London: Springer.

Charmaz, K. (2005). "Grounded Theory in the 21st century: applications for advancing social justice studies". In The Sage Handbook of Qualitative Research, edited by N. K. Denzin and Y. S Lincoln, 507-535. Third Edition. London: Sage Publications.

Denzin, N. K., \& Lincoln, Y. S. (2005). "Introduction: the discipline and the practice of qualitative research". In The Sage Handbook of Qualitative Research, edited by N. K. Denzin and Y. S Lincoln, 1-32. Third Edition. London: Sage Publications. Drake, P. P., \& Fabozzi, F. J. (2009). Foundations and applications of the time value of money. New Jersey: John Wiley \& Sons. 
Fontana, A., \& Frey, J. (2005). "The interview: from neutral stance to political involvement". In The Sage Handbook of Qualitative Research, edited by N. K. Denzin and Y. S Lincoln, 695-727. Third Edition. London: Sage Publications.

Hodkinson, P. (2005). "Reconceptualizing the relations between college-based and working learning”. Journal of Workplace Learning. 17(8), 521-532.

Hoyles, C., Noss, R., Kent, P. \& Bakker, A. (2010.). Improving mathematics at work: the need for techno-mathematical literacies. New York: Routledge.

Hoyles, C., Noss, R., \& Pozzi, S. (2001). "Proportional reasoning in nursing practice". Journal for Research in Mathematics Education. 32(1), 4-27.

Lave, J. \& Wenger, E. (1991). Situated learning: legitimate peripheral participation. New York: Cambridge University Press.

Li, Y., Zhang, J., \& Ma, T. (2009). "Approaches and practices in developing school mathematics textbooks in China". ZDM - The International Journal on Mathematics Education. 41, 733-748.

Mathias, W. F., \& Gomes, J. M. (2011). Matemática Financeira. São Paulo: Atlas.

Murphy, A. (2008). The interface between academic knowledge and working knowledge: implications for curriculum design and pedagogic practices. Level 3, Issue 6, May.

Noss, R. \& Hoyles, C. (1996). "The visibility of meanings: modeling the mathematics of banking". International Journal of Computers for Mathematical Learning. 1, 3-31.

Oliveira, F. D. "Análise de textos didáticos de matemática: um mapeamento e uma proposta metodológica fundada numa perspectiva hermenêutica". Bolema, v.23, n.35B, p.477-496, 2010.

Rezat, S. (2006). "The structures of German mathematics textbooks". ZDM - The International Journal on Mathematics Education. 38(6), 482-487.

Rivera, F., \& Becker, J. R. (2004). A sociocultural account of students' collective mathematical understanding of polynomial inequalities in instrumented activity. Paper presented at $28^{\text {th }}$ Conference Of The International Group For The Psychology Of Mathematics Education, 4. Bergen: IGPME, 81-88.

Samanez, C. P. (2010). Matemática Financeira. São Paulo: Pearson Prentice Hall.

Skovsmose, O. (2000). "Cenários para investigação”. Bolema, 14, 66-91.

Vieira Sobrinho, J. D. (2013). Matemática Financeira. São Paulo: Atlas.

Wedege, T. (2010). Researching workers' mathematics at work. Paper presented at Educational Interfaces Between Mathematics And Industry Conference. Lisboa: Centro Internacional de Matemática, 565-574.

Wenger, E. (1998). Communities of practice: learning, meaning, and identity. New York: Cambridge University Press.

Wertsch, J. V. (1991). Voices of the mind: a sociocultural approach to mediated action. Cambridge: Harvard University Press.

Williams, J., and Wake, G. (2007). "Black boxes in workplace mathematics". Educational Studies in Mathematics. 64, 317-343.

Zevenbergen, R. J. (2011). "Young workers and their dispositions towards mathematics: tensions of a mathematical habitus in the retail industry". Educational Studies in Mathematics. 76, 87-100. 